\title{
Chain mobility in bulky carbosilane modified polymeric siloxane systems
}

\author{
Anna Kowalewska,${ }^{1 *}$ Bogumiła Delczyk, ${ }^{2}$ Jerzy Chruściel ${ }^{3}$
}

${ }^{1 *}$ Centre of Molecular and Macromolecular Studies, Polish Academy of Sciences, Sienkiewicza 112, 90-363 Łódź, Poland; fax: 484268 47126; tel: 484268 03203; email: anko@cbmm.lodz.pl

${ }^{2}$ Centre of Molecular and Macromolecular Studies, Polish Academy of Sciences, Sienkiewicza 112, 90-363 Łódź, Poland; fax: 484268 47126; tel: 484268 03203; email: delczykb@cbmm.lodz.pl

${ }^{3}$ Technical University of Lodz, Institute of Polymer and Dye Technology, Stefanowskiego 12/16, 90-924 Lodz, Poland; fax: 484263 62543; tel: 484263 13200; e-mail: jchrusci@p.lodz.pl

(Received: 4 July, 2008; published: 9 February, 2009)

\begin{abstract}
Hydrosilylation of bulky carbosilanes $\left[\mathrm{CH}_{2}=\mathrm{CHRC}\left(\mathrm{SiMe}_{2} \mathrm{R}^{\prime}\right)_{3}, \mathrm{R}=\mathrm{CH}_{2}\right.$, $\left(\mathrm{CH}_{2}\right)_{3}$ or $\mathrm{SiMe}_{2} ; \mathrm{R}^{\prime}=\mathrm{Me}$ or $\left.\mathrm{Ph}\right]$ with oligosiloxane precursors $\left[\mathrm{M}\left(\mathrm{D}_{2} \mathrm{D}^{\mathrm{H}}\right)_{7} \mathrm{D}_{2} \mathrm{M}\right.$, $\left.M\left(D_{2} D^{H}{ }_{2}\right)_{11} D_{2} M, P D M S_{x \%}-P M H S_{100-x \%}(x=85,50,30,0)\right]$ was carried out. The relationship between the mobility of siloxane chain and the type of carbosilane moiety, as well as the type of distribution of carbosilane group along the polymer chain, was consecutively studied. Carbosilane substituents, due to their exceptional steric requirements, have been shown to strongly affect thermal properties of siloxane oligomers, implying a substantial change of the chain flexibility and free volume of modified oligomers.

Keywords: tris(trimethylsilyl)methane, siloxane, free volume, polymer chain mobility, thermal stability.
\end{abstract}

\section{Introduction}

In our earlier works, important change of properties were reported on modification of polymeric systems with tris(trimethylsilyl)methyl (Tsi) -type groups [1-4]. The materials of such a novel architecture can have potential use as membrane materials in separation processes. Permeability and permselectivity parameters as well as proper mechanical, thermal and surface properties are very important for transport of liquids through polymeric membranes [5]. Therefore, for every system, there is a need for the detailed analysis of the intrinsic mobility of a macromolecule. A systematic study into the effect of divergence of the structure of Tsi-type carbosilane side groups, as well as their distribution along the chain, on the polymer properties has been thus undertaken.

\section{Results and discussion}

Synthesis of Tsi-type carbosilanes with alkenyl functions and linear precursors of the studied oligosiloxanes

The structural diversity of $\mathrm{H}_{2} \mathrm{C}=\mathrm{CHRC}\left(\mathrm{SiMe}_{2} \mathrm{R}^{\prime}\right)_{3}$ (Scheme 1) and various degree of their steric hindrance, allows for preparation of polymeric materials having different 
mobility of the siloxane chain. Tris(trimethylsilyl)methane and tris(phenyldimethyl) methane were prepared by the method of Merker and Scott. [6] They were subsequently lithiated with MeLi [7] and, as earlier described [1, 2, 8], coupled with halogenated alkyl derivatives $\mathrm{XRCH}=\mathrm{CH}_{2}$.
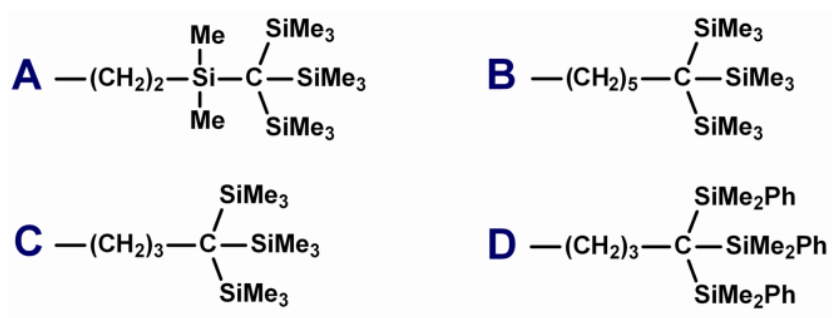

Scheme 1. Structure of Tsi groups in $\mathrm{H}_{2} \mathrm{C}=\mathrm{CHRC}\left(\mathrm{SiMe}_{2} \mathrm{R}^{\prime}\right)_{3}$ used for the studies. [R/R' = -SiMe $\left.{ }_{2}-\mathrm{Me}(\mathbf{A}),-\left(\mathrm{CH}_{2}\right)_{3}-/ \mathrm{Me}(\mathbf{B}),-\mathrm{CH}_{2}-\mathrm{Me}(\mathbf{C}),-\mathrm{CH}_{2}-/ \mathrm{Ph}(\mathbf{D})\right]$.
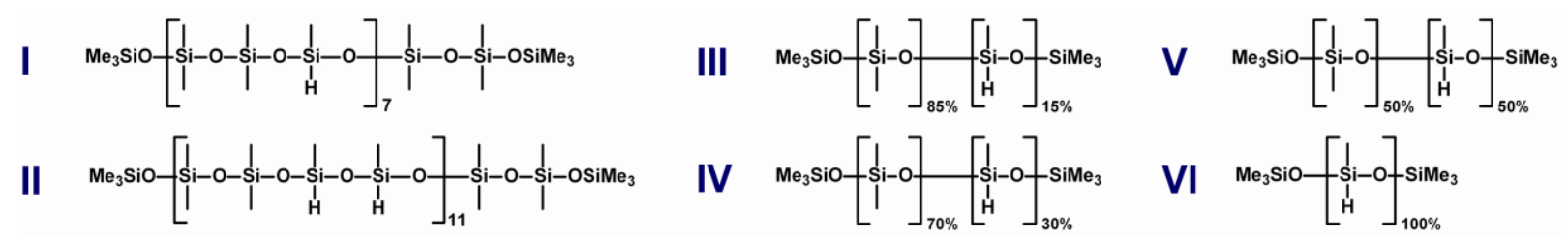

Scheme 2. Structure of siloxane oligomers used for the studies (I and II regular, III-V statistical distribution of Si-H units along the polymer chain).

Two homological series (Scheme 2) of poly(dimethyl-b-methylhydro)siloxanes (I and II) of regular structure, containing single or multiple $-\mathrm{Me}(\mathrm{H}) \mathrm{SiO}$ - units and $\mathrm{Me}_{3} \mathrm{SiO}_{1 / 2}$ end groups were prepared in order to study the influence of bulky side groups distribution on the polymer flexibility. They have been obtained by the controlled heteropolycondensation of $\mathrm{HO}\left(\mathrm{Me}_{2} \mathrm{SiO}\right) \mathrm{SiMe}_{2} \mathrm{OH}$ with $\mathrm{MeHSiCl}_{2}$ or $\mathrm{Cl}(\mathrm{MeHSiO}) \mathrm{SiHMeCl}$, and a consecutive reaction of $\mathrm{HO}$-terminated block polysiloxanes with $\mathrm{Me}_{3} \mathrm{SiCl}$ [9]. Their microstructure was confirmed by ${ }^{29} \mathrm{Si} \mathrm{NMR}$. The regular polymers were compared with their commercially available counterparts, having a statistical distribution of $\mathrm{Si}-\mathrm{H}$ units along the siloxane chain (IV and $\mathrm{V}$ ). Polysiloxane containing $15 \%$ of Si-H functionalized units (III) and PHMS (VI) were used for comparison.

\section{Preparation of polysiloxanes with bulky carbosilane side groups:}

$\mathrm{CH}_{2}=\mathrm{CHRC}\left(\mathrm{SiMe}_{2} \mathrm{R}^{\prime}\right)_{3}$ were hydrosilylated with $\mathrm{Si}-\mathrm{H}$ functionalized siloxanes in the presence of Karstedt's catalyst (Scheme 3 ). The reaction was carried out at RT/343 $\mathrm{K}$ to give $100 \%$ conversion of $\mathrm{Si}-\mathrm{H}$ in all copolymers and about $95 \%$ conversion in the homopolymer $(\mathrm{VI})$. Addition to the double bond proceeded exclusively with $\beta$-product formation. Depending on the amount of Tsi-modified siloxane units, the purified products are brittle either waxy solids, or viscous liquids. For molecular masses (SEC) after the modification increased, but except for the regular polymer I, the rise is smaller than expected especially for bulky carbosilane of type $\mathbf{A}$ (Table 1). The explanation can be a drastic difference in the size and shape of a random coil of the precursor and its Tsi-product. It seems also logical that Tsi $\mathbf{B}$, separated from the main chain by a long alkyl chain, affects less strongly the mobility of the siloxane chain. Absolute masses estimated by the light scattering method are much larger 
than those found by SEC. Polydispersity decrease can be attributed to separation of the highest masses by precipitation into $\mathrm{MeOH}$.

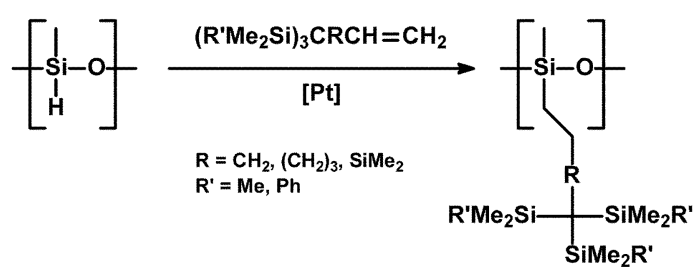

Scheme 3. Preparation of Tsi-siloxanes.

Tab. 1. Characteristics of the studied oligosiloxanes.

\begin{tabular}{|c|c|c|c|c|c|c|c|c|c|c|c|}
\hline \multirow[t]{2}{*}{ siloxane } & \multirow[t]{2}{*}{$\mathrm{R}$} & \multirow[t]{2}{*}{$\% \mathrm{SiR}$} & \multicolumn{2}{|c|}{$M_{\mathrm{NMR}}$} & \multicolumn{2}{|c|}{$M_{n}[D]$} & \multicolumn{2}{|c|}{ PDI } & \multirow{2}{*}{$\begin{array}{c}\mathrm{T}_{\mathrm{g}} \\
{[\mathrm{K}]}\end{array}$} & \multirow{2}{*}{$\begin{array}{c}\Delta \mathrm{T}_{\mathrm{g}} \\
{[\mathrm{K}]}\end{array}$} & \multirow{2}{*}{$\begin{array}{c}\mathrm{Y} \\
{[\%]}\end{array}$} \\
\hline & & & ch.e.a. & $M_{t}$ & $1_{\mathrm{A}}$ & $1_{B}$ & $1_{\mathrm{A}}$ & $1_{\mathrm{B}}$ & & & \\
\hline I & $\mathrm{H}$ & 30 & 1810 & - & 1000 & - & 3.9 & - & 140 & - & - \\
\hline II & $\mathrm{H}$ & 50 & 3300 & - & 3100 & - & 1.9 & - & 139 & - & - \\
\hline III & $\mathrm{H}$ & 15 & 2730 & - & 2300 & - & 2.2 & - & 143 & - & - \\
\hline IV & $\mathrm{H}$ & 30 & 2570 & - & 2600 & - & 1.9 & - & 141 & - & - \\
\hline V & $\mathrm{H}$ & 50 & 1700 & - & 1800 & - & 1.8 & - & 138 & - & - \\
\hline VI & $\mathrm{H}$ & 100 & 3000 & - & 3400 & - & 3.0 & - & 131 & - & - \\
\hline I & $A$ & 30 & 4600 & 4140 & 3700 & 4800 & 3.0 & 1.8 & 260 & 120 & 59.7 \\
\hline II & $A$ & 50 & 15400 & 10890 & 6600 & 15000 & 1.8 & 1.6 & 354 & 215 & 88.4 \\
\hline III & A & 15 & 6800 & 4850 & 4700 & 4300 & 2.0 & 1.9 & 193 & 50 & 72.2 \\
\hline IV & $A$ & 30 & 8130 & 6200 & 5100 & 7700 & 1.7 & 1.5 & 278 & 137 & 78.1 \\
\hline V & $A$ & 50 & 6450 & 5200 & 3300 & 6000 & 1.9 & 1.7 & 328 & 190 & 86.9 \\
\hline VI & $A$ & 93 & 27200 & 18290 & 6600 & 18500 & 2.8 & 3.0 & - & - & 78.4 \\
\hline I & B & 30 & 6310 & 4030 & 3700 & 6500 & 2.9 & 1.7 & 215 & 75 & 71.3 \\
\hline II & B & 50 & 14270 & 10530 & 6300 & 10000 & 1.9 & 1.9 & 263 & 124 & 93.9 \\
\hline III & $B$ & 15 & 5760 & 4750 & 3900 & 5100 & 1.9 & 1.9 & 187 & 44 & 81.8 \\
\hline IV & $B$ & 30 & 7560 & 6030 & 4200 & 7500 & 1.8 & 1.5 & 223 & 82 & 95.6 \\
\hline V & $B$ & 50 & 6200 & 5040 & 3900 & 5900 & 1.7 & 1.8 & 257 & 119 & 83.5 \\
\hline VI & $B$ & 96 & 26530 & 17561 & 8700 & 15500 & 2.5 & 3.3 & 319 & 188 & 95.6 \\
\hline III & C & 15 & 6200 & 4550 & 3600 & 17000 & 2.2 & 1.3 & 160 & 17 & 80.0 \\
\hline III & $D$ & 15 & 7850 & 5810 & 4000 & 6400 & 1.9 & 1.6 & 218 & 75 & 68.3 \\
\hline
\end{tabular}

$\mathrm{R}$ - type of functional moiety at silicon atoms in the main chain [hydride precursors and carbosilanes (according to Scheme 1), methyl groups omitted for clarity].

$\% \mathrm{SiR}$ - amount of functional groups (calculated from ${ }^{1} \mathrm{H}$ NMR).

$\mathrm{M}_{\mathrm{NMR}}$ - molecular mass calculated on the basis of ${ }^{29} \mathrm{Si}$ NMR spectra (ch.e.a. - chain ends analysis, $\mathrm{M}_{\mathrm{t}}$

- theoretical value expected for samples obtained by complete addition of respective bulky carbosilane units to $\mathrm{SiH}$ moieties in the main chain).

$\mathrm{M}_{\mathrm{n}}$ - molecular mass [ $1_{\mathrm{A}}$ - by SEC in $\mathrm{CH}_{2} \mathrm{Cl}_{2}, 1_{\mathrm{B}}$ - by light scattering (MALLS)].

$\mathrm{PDI}$ - polydispersity [ $1_{\mathrm{A}}-$ by SEC in $\mathrm{CH}_{2} \mathrm{Cl}_{2}, 1_{\mathrm{B}}$ - by light scattering (MALLS)].

$\mathrm{T}_{\mathrm{g}}$ - glass transition (20K/min, $2^{\text {nd }}$ heating).

$\Delta \mathrm{T}_{\mathrm{g}}$ - relative increase of $\mathrm{T}_{\mathrm{g}}$.

$\mathrm{Y}-$ the yield of polymer recovered after purification.

Masses $\mathrm{M}_{\mathrm{NMR}}$ obtained by chain end analysis (Table 1, ch.e.a.) in ${ }^{29} \mathrm{Si} \mathrm{NMR}$ as well as those calculated using $\mathrm{M}_{\mathrm{NMR}}$ of hydrido-oligosiloxane precursors and assuming that respective bulky Tsi-type molecules were added to all $\mathrm{SiH}$ groups in polysiloxane chains $\left(M_{t}\right)$ give complementary information about the studied system. We have 
found that masses obtained by chain ends analysis are close to those obtained by MALLS. The discrepancies between $M_{N M R}$ and $M_{n}$ by SEC are more pronounced. Low SEC values, especially those for polymers with bigger amount of trisilated siloxane units, may point out to the change of the size and shape of an average polymer coil in solution after the modification.

\section{Properties of Tsi-polysiloxanes}

A large increase of glass transition temperature $\left(T_{g}\right)$ was observed after modification of all siloxane polymers with bulky carbosilane moieties (Table 1, Figure 1).

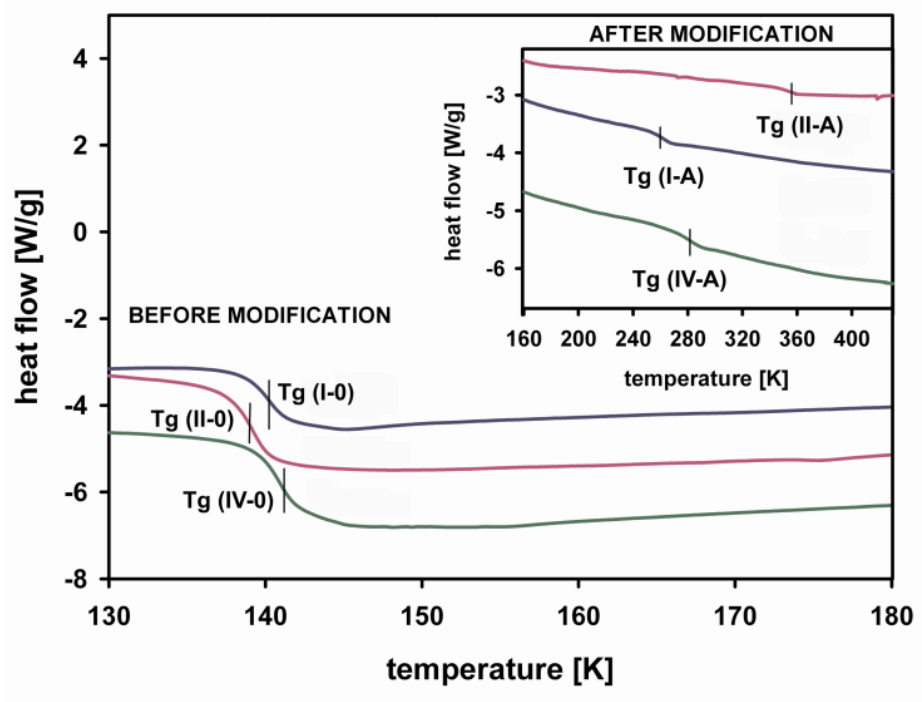

Fig. 1. Exemplary DSC traces for oligosiloxanes of various distribution of functional groups, before and after modification with Tsi-A.

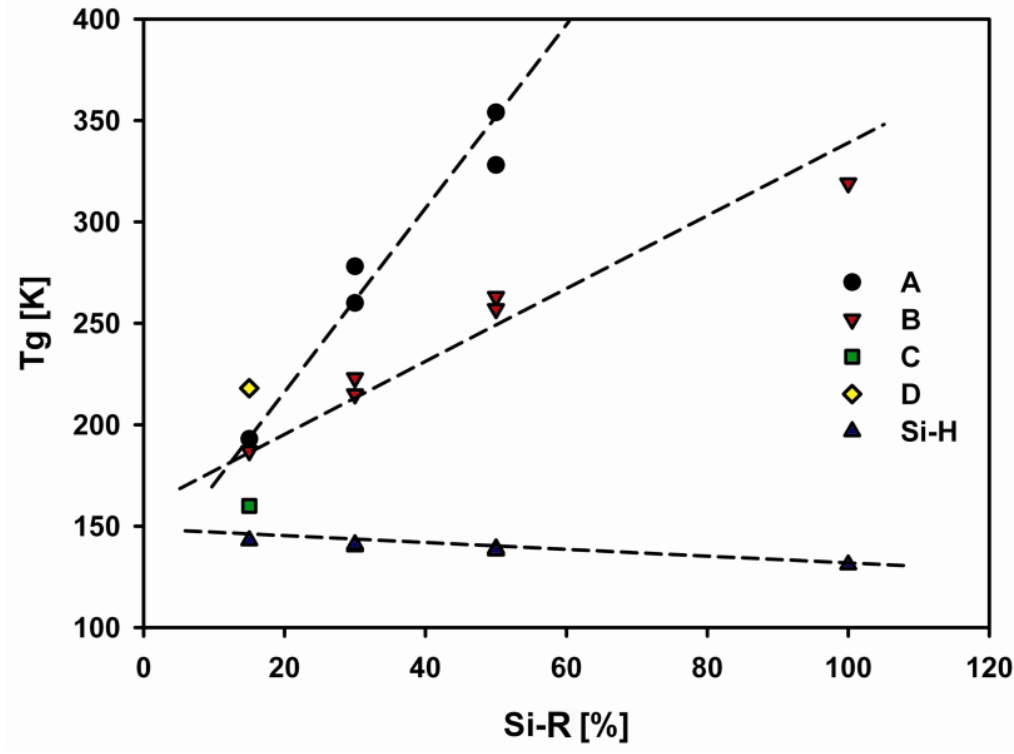

Fig. 2. The dependence of glass transition temperature $\left(T_{g}\right)$ on the type of Tsi group, the linker $\mathrm{R}$ and the amount of carbosilane moieties, for siloxanes with a statistical distribution of Tsi-functions. 
Their Si-H precursors, due to the high flexibility of siloxane chain, generally undergo devitrification at very low temperatures. A slight tendency to decrease $T_{g}$ on increasing the amount of $\mathrm{Si}-\mathrm{H}$ can be observed (Figure 2). As it was expected, bulky Tsi-type side groups are heavy loads to the flexible siloxane chains and restrict the movement of polymer segments. The presence of sterically hindered carbosilanes as side units causes the "anchor effect" to a siloxane chain (increased $T_{g}$ ), but it can be also assumed that an increase of the free volume between polymer chains occurs (however, the latter effect is often associated with a decrease of $T_{g}$ of polymeric systems). The two phenomena are expected to play a significant role in the modification of gas transport through Tsi-polymer membranes.

The type of $R$ and $R^{\prime}$ in the carbosilane unit is very important (Figure 2). Tests carried out with $15 \%$ functionalized units siloxane III have shown that introduction of $\mathrm{Ph}$ containing side group $\mathbf{D}$ leads to $58 \mathrm{~K}$ increase of $\mathrm{T}_{\mathrm{g}}$, comparing to its Me-analog $\mathbf{C}$. The presence of an aromatic group in a Tsi-type molecule increases the steric hindrance and adds to the total size of the side moiety. A coarse modeling the structure of oligosiloxanes with various side groups suggested that modification with molecule $\mathbf{D}$ causes an opening of a random coil of siloxane oligomer. Elongation of the alkyl spacer between the siloxane chain and carbosilane group (B), as well as bringing in a rigid $\mathrm{SiMe}_{2}$ unit in the linker (A), also caused an additional increase of $\mathrm{T}_{\mathrm{g}}$.

Carbosilanes $\mathbf{A}$ and $\mathbf{B}$ were tested in the series of polymers differing by the amount of functionalized units and their distribution along the polymer chain. It was found that the presence of $\mathbf{A}$, connected to polysiloxanes by a rigid spacer, lead to much bigger increase of devitrification temperature (especially for highly functionalized polymers) than $\mathbf{B}$.

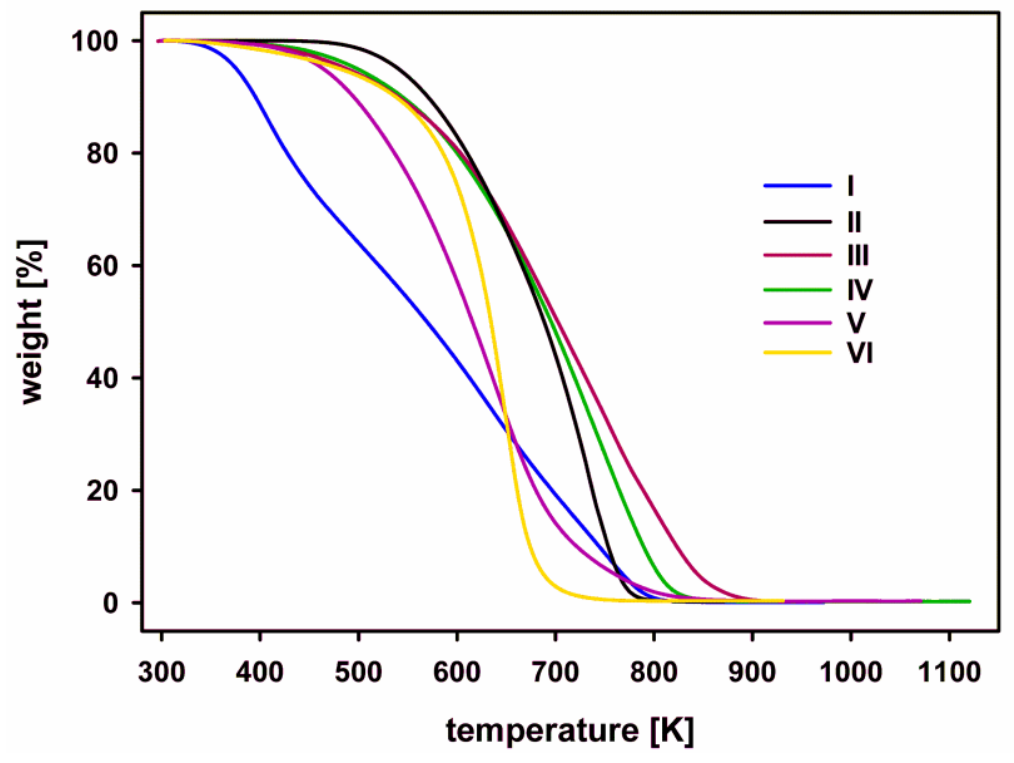

Fig. 3. TGA traces for (Si-H)-siloxane precursors $\left(\mathrm{N}_{2}, 20 \mathrm{~K} / \mathrm{min}\right)$.

Highly flexible $\mathrm{Si}-\mathrm{H}$ functionalized polymers, as well as regular PDMS, decompose thermally by complete depolymerization with formation of cyclic siloxanes (Figure 3) [10]. The presence of bulky Tsi-type carbosilanes hinders this type of depolymerization. Instead, degradation through Si-C scission occurs. Due to the fact 
that in Tsi-type molecules inner Si-C bonds are longer than outer Si-Me (steric strain release) [11], it is thought that they are most thermolysis prone [3]. This can be an explanation to the fact that in spite of larger steric protection provided by $\mathbf{A}$ moieties (Figure 4), the relative weight decrease in series-A is comparable to the one recorded for series-B (Figure 5).

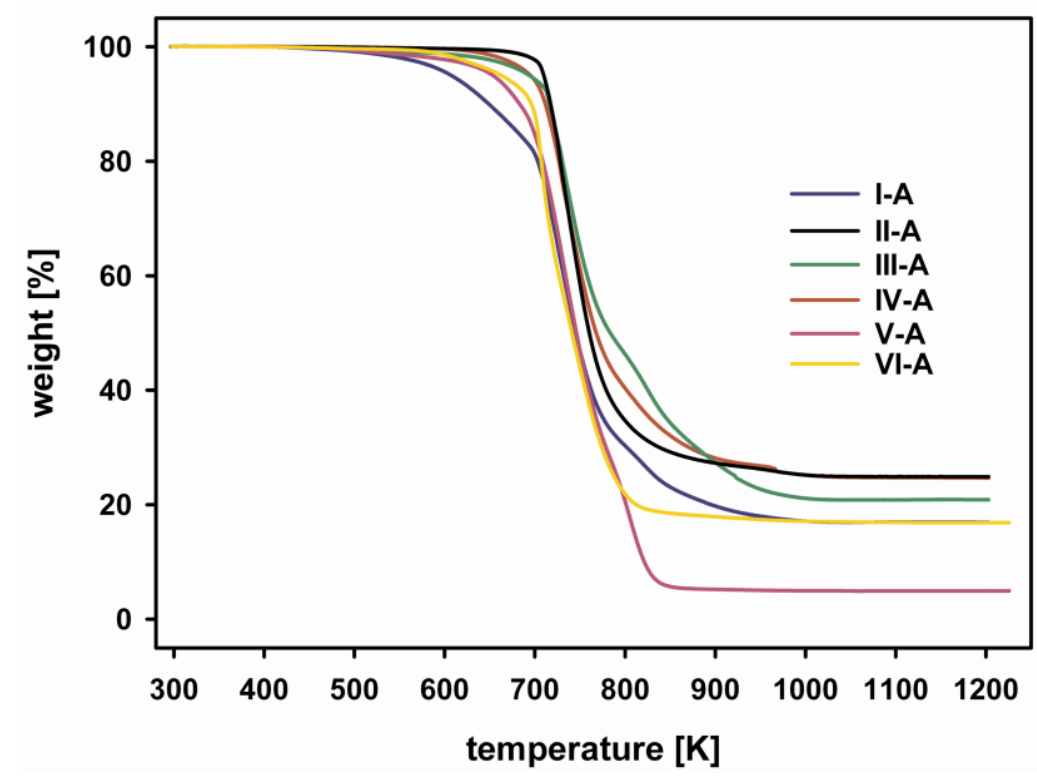

Fig. 4. $T G A$ traces for $\mathbf{A}$-siloxanes $\left(\mathrm{N}_{2}, 20 \mathrm{~K} / \mathrm{min}\right)$.

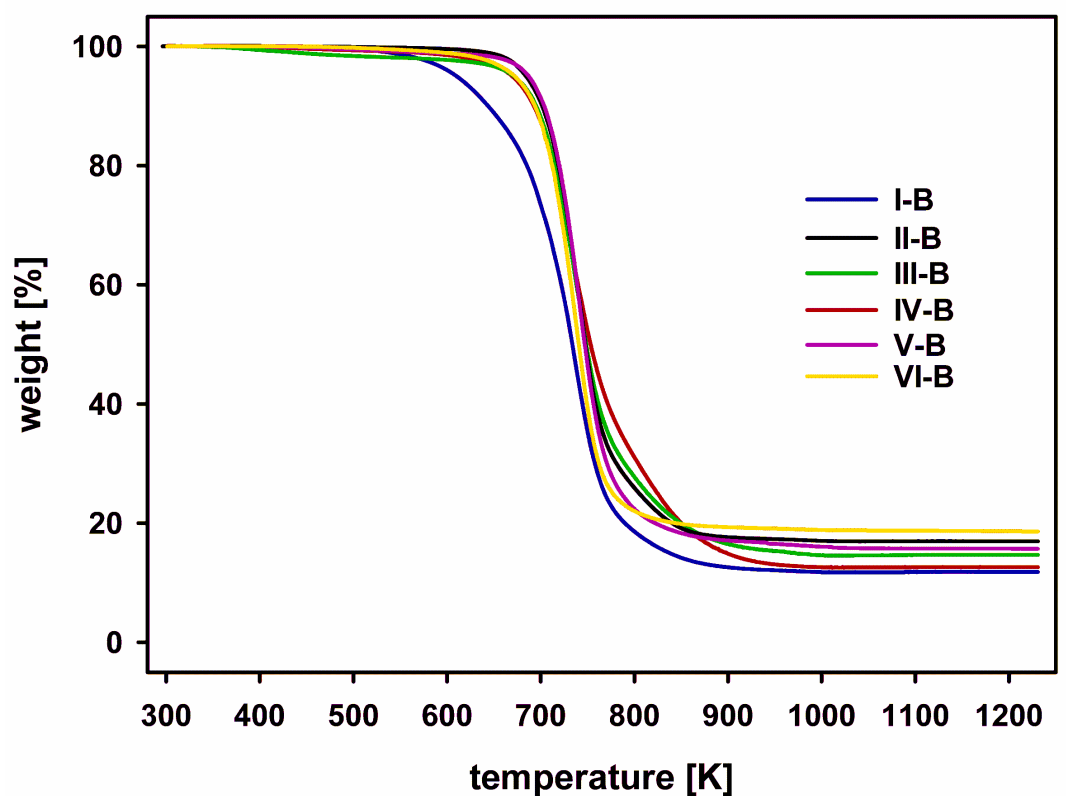

Fig. 5. TGA traces for B-siloxanes $\left(\mathrm{N}_{2}, 20 \mathrm{~K} / \mathrm{min}\right)$.

Comparing the influence of a variety of Tsi groups on the thermal stability of a siloxane copolymer (III), a significant difference can be observed (Figure 6). Carbosilanes A and D, linked to siloxane by $-\mathrm{CH}_{2} \mathrm{CH}_{2} \mathrm{SiMe}_{2}$ unit are most thermally stable. The thermal depolymerization seems to be substantially inhibited for polymers 
III-A and III-D. Polymers with Tsi moiety connected to oligosiloxanes by an alkyl spacer (III-B and especially III-C) are less temperature resistant.

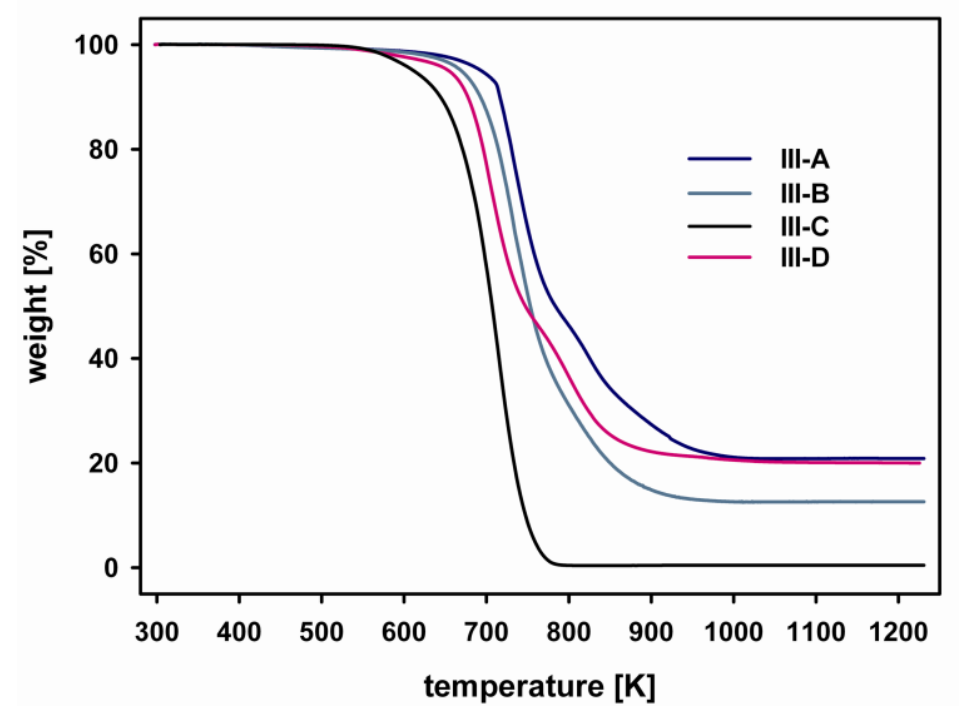

Fig. 6. TGA traces for oligomers with $15 \%$ of siloxane units modified with various Tsi groups $\left(\mathrm{N}_{2}, 20 \mathrm{~K} / \mathrm{min}\right)$.

\section{Conclusions}

A systematic study has shown an enormous impact of sterically hindered Tsi-type carbosilane side groups into the properties of the modified polymers. The rigidity of the otherwise very flexible siloxane chain is enlarged, which was proven by the increase of the temperature of glass to rubber phase transition (devitrification). The adjustment in the structure of Tsi-type groups (including the type of spacer between Tsi and siloxane chain) as well as their distribution along the chain, allows for preparation of polymers of tailored properties. The siloxane materials are promising candidates for selective polymeric membranes. The decreased flexibility of siloxane chains should result in reduced permeability. On the other hand the sheer bulk of Tsitype groups should result in increased free volume within the matrix of a Tsi-siloxane membrane, with the overall final effect being a resultant of the two (permeability studies will be reported).

\section{Experimental part}

\section{Reagents and analytic techniques}

4-[Tris(trimethylsilyl)]-but-1-ene [1], 6-[tris(trimethylsilyl)]-hex-1-ene [2], tris(trimethyl silyl)(vinyldimethy|silyl)methane [8], tris(phenyldimethylsilyl)methane [12] and tris(trimethylsilyl)methane $\mathrm{HC}\left(\mathrm{SiMe}_{3}\right)_{3}[6]$ were prepared according to the respective literature procedures. Trimethylchlorosilane (98\%), bromoform (96\%), nBuLi (2.5 M solution in hexanes), MeLi (1.6 M solution in diethyl ether), pyridine (99\%), dichloromethylsilane (99\%), bromo-1-pentene $(95 \%)$ and allyl bromide $(97 \%)$ were purchased form Aldrich. Platinum divinyltetramethyldisiloxane complex (Karstedt's catalyst, $3 \%$ solution in xylenes), chlorodimethylvinylsilane $(97 \%)$, phenyldimethylchlorosilane $(97 \%)$ and 1,3-dichlorotetramethyldisiloxane $(97 \%)$ were bought from ABCR. Solvents (tetrahydrofurane, diethyl ether, pentane, methylene chloride, ethyl alcohol, acetone) were supplied by POCh (Polish Chemical 
Reagents). All solvents were carefully dried according to literature procedures [13] and distilled prior to their use. Other reagents were used as received.

NMR spectra were recorded, in $\mathrm{CDCl}_{3}$ as a solvent, on Bruker $\mathrm{AC}-200 \mathrm{MHz}\left({ }^{1} \mathrm{H}\right.$ NMR) or DRX-500 MHz $\left({ }^{13} \mathrm{C}\right.$ and $\left.{ }^{29} \mathrm{Si} \mathrm{NMR}\right)$ spectrometers with $\mathrm{TMS}$ as the reference. GC-MS Cl+ analysis was by a Finnigan MAT 95 spectrometer at $70 \mathrm{eV}$.

Size exclusion chromatography (SEC) was performed using Wyatt Optilab 903 apparatus [LKB $2150 \mathrm{HPLC}$ pumps, dual detector MALLS (Multiangle Laser Light Scattering)/RI, two (TSK G4000HLX and G2000HLX) columns, eluent $-\mathrm{CH}_{2} \mathrm{Cl}_{2}(0.8$ $\mathrm{ml} / \mathrm{min})$ ]. Molecular masses were derived from a calibration curve based on polystyrene standards.

Phase transitions of polymers were studied by differential scanning calorimetry (DSC) technique (DuPont 2000 thermal analysis system). Thermograms were taken for samples (sealed in aluminium pans) quenched rapidly from the melt (room temperature) and then heated at the rate of $10 \mathrm{~K} / \mathrm{min}$ (selected samples were heated also at $20 \mathrm{~K} / \mathrm{min}$ ) from $118 \mathrm{~K}$ to $323 \mathrm{~K}$. The sample was kept at $323 \mathrm{~K}$ for 3 minutes to destroy any thermal history. Subsequently, it was quenched to $118 \mathrm{~K}$ and heated again at $20 \mathrm{~K} / \mathrm{min}$. Each thermal treatment was repeated 2 times for each sample. The transition temperatures were taken as corresponding to the maximum of the enthalpic peak.

Thermogravimetric measurements were performed by use of a Hi-Res TGA 2950 Thermogravimetric Analyzer (TA Instruments) in nitrogen atmosphere (heating rate $20 \mathrm{~K} / \mathrm{min}$, resolution 3 , sensitivity 3 ).

\section{Synthetic procedures}

-Synthesis of 4-[tris(phenyldimethylsilyl)]-but-1-ene

$7.0 \mathrm{ml}$ of MeLi in diethyl ether $(1.6 \mathrm{M}$ solution, $0.011 \mathrm{~mol})$ was placed in a Schlenk's flask. Volatiles were removed under vacuum and a solution of $\mathrm{HC}\left(\mathrm{SiMe}_{2} \mathrm{Ph}\right)_{3}(3.5 \mathrm{~g}$, $0.0084 \mathrm{~mol})$ in THF $(15 \mathrm{ml}$ ) was added. The solution became yellowish only after 10 minutes of stirring at room temperature. It was stirred at $343 \mathrm{~K}$ for additional 2 hours and then cooled to room temperature. Allyl bromide $(1.0 \mathrm{ml}, 0.0116 \mathrm{~mol})$ was added drop-wise at room temperature to the prepared solution $\mathrm{LiC}\left(\mathrm{SiMe}_{2} \mathrm{Ph}\right)_{3} / \mathrm{THF}$. The mixture gradually became colourless. The mixture was then stirred for additional 24 hours at $343 \mathrm{~K}$. Volatiles were removed under reduced pressure, and the product was dissolved in diethyl ether $(100 \mathrm{ml})$. The solution was washed with cold water to neutral $\mathrm{pH}$ and dried over $\mathrm{MgSO}_{4}$, then separated. The crude product, after volatiles removal on a rotary evaporator, was crystallized from $\mathrm{MeOH}$ to leave a solid material - pure $\left(\mathrm{PhMe}_{2} \mathrm{Si}_{3}\right)_{3} \mathrm{CCH}_{2} \mathrm{CH}=\mathrm{CH}_{2}(2.7 \mathrm{~g}, \mathrm{Y}=70 \%)$.

$\left(\mathrm{PhMe}_{2} \mathrm{Si}_{3} \mathrm{CCH}_{2} \mathrm{CH}=\mathrm{CH}_{2}\right.$ :

${ }^{1} \mathrm{H}$ NMR ( $\left.\sigma \mathrm{ppm}\right): 0.19$ (s) $\mathrm{SiMe}_{2} \mathrm{Ph}(18 \mathrm{H}), 3.0(\mathrm{~d}) \mathrm{CH}_{2}(2 \mathrm{H}), 5.14(\mathrm{~m})=\mathrm{CH}_{2}(1 \mathrm{H}), 5.25$ $(\mathrm{m})=\mathrm{CH}_{2}(1 \mathrm{H}), 6.20(\mathrm{~m})-\mathrm{CH}=(1 \mathrm{H}), 7.1-7.6 \mathrm{Ph}$

${ }^{13} \mathrm{C} \mathrm{NMR}(\sigma \mathrm{ppm}): 1.1 \mathrm{SiMe}_{2} \mathrm{Ph}, 10.5 \mathrm{CH}_{2},(127.5,128.6,135.2,141.0) \mathrm{Ph}, 115.9$ $=\mathrm{CH}_{2}, 140.7-\mathrm{CH}=$

${ }^{29} \mathrm{Si} \mathrm{NMR}(\sigma \mathrm{ppm}):-2.4 \mathrm{SiMe}_{2} \mathrm{Ph}$

MS-Cl (m/z): $\left.443(\mathrm{M}-\mathrm{Me})^{+}, 1 \% ; 354,3 \% ; 246,5 \% ; 231,12 \% ; 197 \mathrm{MeSiPh}_{2}\right)^{+} 14 \%$; $135\left(\mathrm{Me}_{2} \mathrm{PhSi}\right)^{+}$100\%; $73\left(\mathrm{SiMe}_{3}\right)^{+} 3 \%$ 
-Preparation of poly(dimethyl-b-methylhydro)siloxanes (I and II) of regular structure (a general procedure) [9]

Poly(dimethyl- $b$-methylhydro)siloxanes of regular structure $\left\{\mathrm{Me}_{3} \mathrm{SiO}\left[\left(\mathrm{Me}_{2} \mathrm{SiO}\right)_{2-}\right.\right.$ $(\mathrm{MeHSiO})]_{7}\left(\mathrm{Me}_{2} \mathrm{SiO}\right)_{2} \mathrm{SiMe}_{3}$ and $\left.\mathrm{Me}_{3} \mathrm{SiO}\left[\left(\mathrm{Me}_{2} \mathrm{SiO}\right)_{2}(\mathrm{MeHSiO})_{2}\right]_{11}\left(\mathrm{Me}_{2} \mathrm{SiO}\right)_{2} \mathrm{SiMe}_{3}\right\}$ were prepared by heteropolycondensation of dimethylsiloxanediols $\mathrm{HO}\left(\mathrm{Me}_{2} \mathrm{SiO}\right)_{2} \mathrm{H}$ respectively with equimolar amounts of $\mathrm{MeHSiCl}_{2}$ or $\mathrm{Cl}(\mathrm{MeHSi}) \mathrm{O}(\mathrm{SiHMe}) \mathrm{Cl}$. One of substrates - telechelic dimethylsiloxanediol $\mathrm{HO}\left(\mathrm{Me}_{2} \mathrm{SiO}\right)_{2} \mathrm{H}$ was prepared by hydrolysis of $\alpha$,w-dichlorosiloxane $\mathrm{Cl}\left(\mathrm{Me}_{2}\right) \mathrm{SiOSi}\left(\mathrm{Me}_{2}\right) \mathrm{Cl}$, carried out in $\mathrm{Et}_{2} \mathrm{O}$, with pyridine as the acceptor of generated hydrochloride. $\alpha, \omega$-Dichloromethyl hydrodisiloxane $\mathrm{Cl}(\mathrm{MeHSi}) \mathrm{O}(\mathrm{SiHMe}) \mathrm{Cl}$ was prepared by partial hydrolysis of methyldichlorosilane in $\mathrm{Et}_{2} \mathrm{O}$, carried out at 200-290 K. The product was distilled under reduced pressure, and a fraction boiling at $376 \mathrm{~K} / 99.7 \mathrm{kPa}$ was collected.

The prepared samples of silanol-terminated poly(dimethyl-b-methylhydro)siloxanes of regular blocks distribution were successively coupled with two fold excess of $\mathrm{Me}_{3} \mathrm{SiCl}$. Polycondensation reactions of siloxanediols with $\mathrm{Me}_{3} \mathrm{SiCl}$ were carried out in $\mathrm{Et}_{2} \mathrm{O}$ at low temperature $(270 \mathrm{~K})$, in the presence of pyridine as the acceptor of $\mathrm{HCl}$. After filtration and solvent removal under reduced pressure at room temperature, all poly(dimethyl-b-methylhydro)siloxanes were heated under high vacuum $(7 \mathrm{~Pa})$ for $\sim 2 \mathrm{hrs}$ at high temperature in order to remove all volatile impurities.

$\mathrm{Me}_{3} \mathrm{SiO}\left[\left(\mathrm{Me}_{2} \mathrm{SiO}\right)_{2}(\mathrm{MeHSiO})\right]_{7}\left(\mathrm{Me}_{2} \mathrm{SiO}\right)_{2} \mathrm{SiMe}_{3}$ :

${ }^{29} \mathrm{Si} \mathrm{NMR}(\sigma \mathrm{ppm}): 7.30 \mathrm{Me}_{3} \mathrm{SiO}-,-20.38 \mathrm{DDD}{ }^{\mathrm{H}},-21.45 \underline{D} D^{\mathrm{H}},-37.30 \underline{D D}^{\mathrm{H}} \mathrm{D}$

$\mathrm{Me}_{3} \mathrm{SiO}\left[\left(\mathrm{Me}_{2} \mathrm{SiO}\right)_{2}(\mathrm{MeHSiO})_{2}\right]_{11}\left(\mathrm{Me}_{2} \mathrm{SiO}\right)_{2} \mathrm{SiMe}_{3}$ :

${ }^{29} \mathrm{Si} \mathrm{NMR}(\sigma \mathrm{ppm}): 7.45 \mathrm{Me}_{3} \mathrm{SiO}-,-19.74 \mathrm{DD} D^{\mathrm{H}},-20.28 \underline{D D} D^{\mathrm{H}},-36.06 \mathrm{D} \underline{\mathrm{H}}^{\mathrm{H}} \mathrm{D}^{\mathrm{H}},-36.11$ $D D^{H} \underline{D}^{H}$

Tab. 2. Exemplary NMR chemical shifts of Tsi-siloxanes (oligomer V).

\begin{tabular}{|c|c|c|c|c|c|c|c|c|c|c|c|c|}
\hline \multirow[t]{2}{*}{ unit / Tsi } & \multicolumn{3}{|c|}{$\mathrm{A}(\sigma \mathrm{ppm})$} & \multicolumn{3}{|c|}{$\mathrm{B}(\sigma \mathrm{ppm})$} & \multicolumn{3}{|c|}{$\mathrm{C}(\sigma \mathrm{ppm})$} & \multicolumn{3}{|c|}{$\mathrm{D}(\sigma \mathrm{ppm})$} \\
\hline & ${ }^{1} \mathrm{H}$ & ${ }^{13} \mathrm{C}$ & ${ }^{29} \mathrm{Si}$ & ${ }^{1} \mathrm{H}$ & ${ }^{13} \mathrm{C}$ & ${ }^{29} \mathrm{Si}$ & ${ }^{1} \mathrm{H}$ & ${ }^{13} \mathrm{C}$ & ${ }^{29} \mathrm{Si}$ & ${ }^{1} \mathrm{H}$ & ${ }^{13} \mathrm{C}$ & ${ }^{29} \mathrm{Si}$ \\
\hline $\mathrm{SiMe}_{3}$ & 0.23 & 5.7 & -1.8 & 0.13 & 2.9 & 2.1 & 0.12 & 2.5 & 2.3 & - & - & - \\
\hline $\mathrm{SiMe}_{2} \mathrm{Ph}$ & - & - & - & - & - & - & - & - & - & 0.17 & 1.0 & -3.0 \\
\hline $\mathrm{SiMe}_{2}$ & 0.20 & 1.6 & 2.2 & - & - & - & - & - & - & - & - & - \\
\hline $\mathrm{CH}_{2(1)}$ & 0.40 & 10.8 & - & 0.51 & 17.9 & - & 0.50 & 19.9 & - & 0.7 & 21.0 & - \\
\hline $\mathrm{CH}_{2(2)}$ & 0.70 & 10.5 & - & 1.35 & 23.0 & - & 1.70 & 23.9 & - & 1.9 & 25.0 & - \\
\hline $\mathrm{CH}_{2(3)}$ & - & - & - & 1.28 & 35.2 & - & 1.70 & 35.7 & - & 1.9 & 37.0 & - \\
\hline $\mathrm{CH}_{2(4)}$ & - & . & - & 1.50 & 30.0 & - & - & - & - & - & - & - \\
\hline $\mathrm{CH}_{2(5)}$ & - & - & - & 1.62 & 31.2 & - & - & - & - & - & - & - \\
\hline $\mathrm{OSiMe}_{3}$ & 0.10 & 5.7 & 7.0 & 0.07 & 2.9 & 7.0 & 0.08 & 2.5 & 7.5 & 0.08 & 2.5 & 7.0 \\
\hline$-\mathrm{SiMe}_{2} \mathrm{O}-$ & 0.23 & -0.9 & & 0.13 & -0.2 & _ & 0.12 & -0.3 & - & 0.12 & -0.4 & - \\
\hline & & & 22.0 & & & 22.9 & & & 21.8 & & & 21.0 \\
\hline - & 0.23 & -0.9 & - & 0.13 & -0.2 & - & 0.12 & -0.3 & - & 0.12 & -0.4 & - \\
\hline SiMe(Tsi)O- & & & 22.0 & & & 22.9 & & & 21.8 & & & 21.0 \\
\hline $\mathrm{Ph}$ & - & - & - & - & - & - & - & - & - & $\begin{array}{r}7.0- \\
7.5\end{array}$ & $\begin{array}{r}127- \\
141\end{array}$ & - \\
\hline $\mathrm{C}_{\mathrm{q}}$ & - & $1.43^{-}$ & - & - & 6.22 & - & - & 6.86 & - & - & - & - \\
\hline
\end{tabular}


-General procedure for modification of siloxane precursors

The reaction was carried out according to a modification of the standard procedure [1]. Tsi-alkene $\left(0.14 \mathrm{~mol} / \mathrm{dm}^{3}\right.$ solution in toluene) was stirred with Karstedt's catalyst ([Pt $\left.] /\left[\mathrm{CH}_{2}=\mathrm{CH}\right]=1 \times 10^{-4}\right)$ at room temperature for $20 \mathrm{~min}$. A solution of $\mathrm{Si}-\mathrm{H}$ siloxane in toluene $\left(1.1 \mathrm{~mol} / \mathrm{dm}^{3}\right.$ of $\mathrm{Si}-\mathrm{H}$ groups) was added drop-wise and the reaction mixture $\left([\mathrm{Si}-\mathrm{H}] /\left[\mathrm{CH}_{2}=\mathrm{CH}\right]=0.9\right)$ was stirred for 30 minutes at room temperature. Then, in order to achieve total conversion of $\mathrm{Si}-\mathrm{H}$ bonds, the mixture was stirred for several days at $343 \mathrm{~K}$. Progress of the reaction was followed by ${ }^{1} \mathrm{H}$ NMR. Once the addition of $\mathrm{Si}-\mathrm{H}$ to $\mathrm{CH}_{2}=\mathrm{CH}$ was completed, the volatiles were removed under reduced pressure, and the product was dissolved in $\mathrm{CH}_{2} \mathrm{Cl}_{2}$, precipitated into a large volume of $\mathrm{MeOH}$ (repeated 3 times), and dried at $310 \mathrm{~K}$ under high vacuum to leave an appropriate Tsi-siloxane.

\section{Acknowledgements}

We thank Polish Ministry of Science and Higher Education for the support within Grant N205-1965-33.

\section{References}

[1] Kowalewska, A.; Stańczyk, W.A.; Boileau, S.; Lestel, L.; Smith, J.D. Polymer 1999, 40, 813.

[2] Kowalewska, A.; Stańczyk, W.A. Chem. Mater. 2003, 15, 2991.

[3] Kowalewska, A.; Kupcik, J.; Pola, J.; Stańczyk, W.A. Polymer 2008, 49, 857.

[4] Kowalewska, A. J. Organomet. Chem. 2008, 693, 2193.

[5] Wang, X.Y.; Hill, A.J.; Freeman, B.D.; Sanchez, I.C. J.Membrane Sci. 2008, 314, 15.

[6] Merker, R.L.; Scott, M.J. J. Am. Chem. Soc., 1963, 85, 2243.

[7] Aiube, Z.H.; Eaborn, C. J. Organomet. Chem. 1984, 269, 217.

[8] Kowalewska, A.; Fortuniak, W. (submitted).

[9] Chruściel, J.; Kulpiński, J.; Romanowski, Z. Zeszyty naukowe Politechniki Śląskiej (seria Chemia) 1999, 140, 109.

[10] Kendrick, T.C.; Parbhoo, B.; White, J.W. in The Chemistry of Organic Silicon Compounds; Patai, S., Rappaport, Z. (Eds.), Wiley, Chichester, 1989; pp 1319-1341.

[11] Eaborn, C; Smith, J.D. J Chem Soc Dalton Trans 2001, 10, 1541.

[12] Eaborn, C; Hitchcock P.B., Lickiss, P.D. J. Organomet. Chem. 1984, 269, 235.

[13] Perrin, D.D.; Armarego, W.L.F. Purification of Laboratory Chemicals, Pergamon Press, Oxford, 1980. 